\title{
The Recommendation Of Space Lay Out On Children Autis School IN SURAKARTA
}

\author{
Rekomendasi Penataan Ruang Pada Sekolah anak autis \\ Di Wilayah SURAKarTa
}

\author{
Musyawaroh $^{1 *}$, Edi Pramono Singgih ${ }^{2}$, Trijoko Daryanto ${ }^{3}$, Sumaryoto $^{4}$ \\ Prodi Arsitektur, Fakultas Teknik, Universitas Sebelas Maret ${ }^{1}$ \\ Email : musysofwan@gmail.com* \\ Prodi Arsitektur, Fakultas Teknik, Universitas Sebelas Maret ${ }^{2}$ \\ Prodi Arsitektur, Fakultas Teknik, Universitas Sebelas Maret ${ }^{3}$ \\ Prodi Arsitektur, Fakultas Teknik, Universitas Sebelas Maret ${ }^{4}$
}

\begin{abstract}
The number of autism sufferers worldwide is increasing, but not yet followed by optimal handling. The cost of autism therapy is unaffordable by the general public because of the need for a specific and expensive container. Need to improve the quality of handling, especially in space for activities that contribute to the process of autism therapy.

In this study, an evaluation of the autism school in Surakarta and surrounding areas and made recommendations for solutions to the existing problems. The method used is qualitative rationalistic with post-occupancy indicative evaluation. Data obtained from field observation of research object, interview with related parties, and literature study. The data obtained is processed by emphasizing the meaning of empiri, understanding and intellectual ability to argue logically with supported empirical data and relevant theory. From the results of these evaluations, prepared spatial planning recommendations based on design criteria that are positively oriented towards increasing autism independence. From the results of the study known that the existing space can be used quite well, although technically inadequate, need improvement in order to function more optimally. The results of this study are expected to be used as a reference for autism school planning in the future.
\end{abstract}

Keywords: Recommendations, space layout, children autis school

\section{PENDAHULUAN}

Dalam kurun waktu 10 tahun terakhir ini masalah autisme meningkat pesat di seluruh dunia termasuk di Indonesia, jumlah anak autis di indonesia pada tahun 2015 kurang lebih 12.800 dan 134.000 penyandang spektrum Autis (Judarwanto, 1943).

Kondisi pusat terapi di Indonesia belum sebanding dengan jumlah penderita yang ada, fasilitas ruang dan perlengkapan yang tersediapun belum memenuhi kebutuhan (Mayang Sari, 2004). Hingga kini belum ada proses belajar mengajar yang baku, bahkan mereka dipandang sebagai beban. Kebutuhan anak autis perlu ditanggapi dengan melakukan proses rancang bangun yang merespon kebutuhan tersebut yang tidak hanya memfasilitasi kegiatan terapi, pembelajaran akan tetapi sekaligus melatih anak agar bisa mandiri (Altenmüller-lewis, 2017).

Penelitian yang membahas tentang tata ruang di sekolah autis sangat diperlukan agar dapat memberikan solusi permasalahan berupa rekomendasi atau arahan desain yang menghasilkan penataan yang lebih optimal dan diharapkan dapat menghasilkan anak autis yang mandiri, survive, eksis, dan dapat hidup 
seperti anak-anak lain pada umumnya. Selain hal itu, penelitian yang membahas tentang tata ruang dibutuhkan, karena penelitian yang telah dilakukan sebelumnya belum ada yang membahas tata ruang secara spesifik.

Dari uraian tersebut di atas, permasalahan yang akan diangkat adalah :

a. Bagaimana kondisi tata ruang di sekolah autis yang ada di Surakarta dan sekitarnya?

b. Bagaimana rekomendasi penataan ruang yang lebih baik?

Adapun tujuan penelitian ini adalah sebagai berikut.

a. Mengevaluasi kekurangan dan kelebihan tata ruang di sekolah autis yang ada di Surakarta dan sekitarnya.

b. Merumuskan rekomendasi penataan ruang yang lebih baik bagi Sekolah anak autis.

Kajian teoritik tentang autis diperlukan untuk dapat memberikan perspektif yang sesuai dalam menyelesaikan permasalahan tersebut di atas. Secara umum autis merupakan kumpulan gejala gangguan perilaku yang bervariasi pada setiap anak, gangguan tersebut berupa kurangnya interaksi sosial, penghindaran kontak mata, kesulitan dalam mengembangkan bahasa dan pengulangan tingkah laku (Sari, 2014). Anak autis mengalami hambatan dalam perkembangan perilakunya, antara lain perilaku wicara dan okupasi, padahal kedua jenis perilaku ini penting untuk komunikasi dan sosialisasi. Sehingga apabila hambatan ini tidak diatasi dengan cepat dan tepat, maka proses belajar anak-anak tersebut juga akan terhambat. Intelegensi, emosi dan perilaku sosialnya tidak dapat berkembang dengan baik.

Lingkungan di mana manusia berada tidak sepenuhnya sesuai dengan apa yang dibutuhkan atau diinginkan. Anak autis memiliki sensitivitas tinggi terhadap lingkungan di mana ia berada. Anak autis kurang memiliki kepekaan sosial, akan tetapi mampu menyadari perbedaan-perbedaan kecil yang ada di lingkungan sekitarnya. Maka dari itu, lingkungan anak autis dikondisikan untuk sedemikian rupa untuk memaksimalkan kenyamanan agar mereka dapat mandiri. Rancangan sebuah bangunan / ruangan dapat mempengaruhi opsi yang akan dipilih oleh penggunanya dari berbagai sudut pandang, yakni : Permeability, variety, legibility, appropriateness, richness, personalitation (Altenmüller-lewis, 2017).

Untuk mengetahui tingkat keberhasilan/kinerja suatu bangunan setelah ditempati, dilakukan Evaluasi Purna Huni (EPH) atau Post Occupancy Evaluation (POE). EPH yang dilakukan untuk penelitian ini adalah indikatif $P O E$, yang mengemukakan tentang indikasi tingkat keberhasilan bangunan meliputi : 1) Teknis, yang meliputi zona fisik tata ruang; 2) fungsional, yaitu proses kegiatan yg terjadi di lingkungan; 3) perilaku, meliputi perilaku penghuni yang terjadi di dalam lingkungan tersebut (Altenmüller-lewis, 2017).

Untuk mengetahui kriteria yang dibutuhkan dalam menyusun tata ruang, digunakan teori desain sensorik dan autisme aspek indeks (telah diterapkan dalam desain Sekolah autis di Amerika) yakni: Konteks dan komunitas (context and community); zonning; wayfinding, navigation, circulation and spatial sequencing; pencahayaan alami/buatan; penyelamatan kebakaran dan evakuasi (fire safety and evacuation) (Hosny \& Anous, 2015).

\section{METODE}

Lokasi penelitian adalah sekolah khusus untuk anak autis yang di wilayah Surakarta dan sekitarnya, yang diambil sebagai obyek observasi yaitu Sekolah Autis Mitra Ananda di Colomadu Karanganyar dan Sekolah Autis Harmony di Sangkrah Pasar Kliwon Surakarta.

Penelitian ini menggunakan pendekatan Kualitatif Rasionalistik. Sumber data terdiri dari data primer berupa informasi tentang sekolah autis yang diperoleh secara representatives dari siswa, guru dan pengelola pada sekolah anak autis. Data sekunder berupa pembahasan dan peraturan tentang anak autis, diperoleh dari literatur, internet dan penelitian sebelumnya. Teknik pengambilan sampel secara porpusive, diambil sampel yang dianggap dapat mewakili kasusnya.

Hasil observasi, wawancara, studi literatur diidentifikasi \& direduksi berdasarkan itemitem yang telah ditetapkan. Selanjutnya data dianalisa menggunakan model Analisis Interaktif analisis secara interaktif dan 
berlangsung secara terus menerus sampai tuntas, sehingga datanya jenuh (Huberman, 1994). Untuk lebih jelasnya lihat gambar 1.

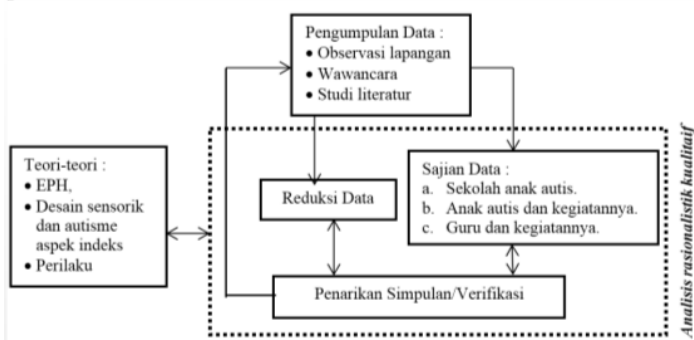

Gambar 1. Model Analisis Interaktif,

Sumber : Dikembangkan dari (Huberman, 1994)

Teori-teori yang digunakan untuk menganalisis adalah teori EPH, teori desain sensorik dan autisme aspek indeks, dan perilaku pengguna. Aktivitas dalam analisis meliputi reduksi data, penyajian data serta penarikan kesimpulan dan verifikasi.

\section{HASIL DAN PEMBAHASAN}

Ruang sebagai salah satu komponen arsitektur (bagian dari bangunan) berfungsi sebagai wadah bagi kegiatan manusia. Perilaku sebagai bentuk kegiatan manusia membutuhkan seting / tempat yang mewadahi yang berbentuk ruang (Setiawan, 2010). Bangunan sebagai lingkungan binaan/buatan berkaitan erat dengan perilaku penghuninya. Pengkajian lingkungan- perilaku dilakukan untuk mengetahui bagaimana lingkungan buatan dapat melayani kebutuhan manusia/penghuni dengan sebaik-baiknya (Moore, 1979).

\section{Evaluasi Terhadap Sekolah Autis Yang Ada Di Surakarta Dan Sekitarnya.}

Untuk mengetahui tingkat keberhasilan/kinerja dari obyek penelitian setelah ditempati, dilakukan Evaluasi Purna Huni (EPH) atau Post Occupancy Evaluation (POE) . EPH yang dilakukan untuk penelitian ini adalah indikatif $P O E$, yang mengemukakan tentang indikasi tingkat keberhasilan bangunan meliputi : 1) Teknis, yang meliputi zona fisik tata ruang; 2) fungsional, yaitu proses kegiatan yg terjadi dalam bangunan; 3) perilaku, meliputi perilaku penghuni yang terjadi dalam bangunan (Akman, 2002).
Teori yang digunakan untuk mengevaluasi tata ruang pada sekolah untuk anak autis yang ada berasal dari penggabungan teori desain sensorik dan autisme aspek indeks Anous dan teori rancangan sebuah bangunan/ruangan, setelah disesuaikan dengan kebutuhan anak autis penggabungan tersebut menjadi sebagai berikut (Hosny \& Anous, 2015).

1) Zonning (pengelompokan spasial) dan organisasi ruang.

- Mengelompokkan (zonning) dan membagi ruang (compartmentalization) sesuai dengan tingkatan privasi yang dibutuhkan.

- Mengembangkan penggunaan ruang (personalitation) secara multi fungsi (robustness),

2) Konteks dan Komunitas (Context and Community).

Menciptakan kesempatan untuk interaksi antar siswa, guru/pembimbing dan masyarakat.

3) Way-finding, Navigation, Circulation.

Menggunakan sistem sirkulasi satu arah. Tujuannya adalah mengarahkan alur sirkulasi anak (permeability) dengan memberikan tampilan detail arsitektural (appropriateness) melalui alat bantu visual seperti warna, pola, tekstur, kata-kata tertulis dan signage menggunakan bahan kontras pada berbagai elemen lantai, dinding, langit-langit, pintu.

4) Akustik, pencahayaan alami/buatan dan penghawaan.

- Pencahayaan yang digunakan menghindari silau dan silhouetting.

- Penghawaan yang nyaman.

- Menghindari bising.

5) Keamanan, penyelamatan kebakaran dan evakuasi bencana (fire safety and evacuation).

- Menggunakan elemen interior yang aman bagi anak autis

- Menyediakan jalur evakuasi yang aman dan efektif.

Evaluasi Terhadap Sekolah Autis Yang Ada Di wilayah Surakarta adalah sebagai berikut.

\section{a. Evaluasi Teknis}

Dari dua sekolah anak autis yang dijadikan obyek penelitian, dilakukan evaluasi secara 
teknis terhadap kondisi tata ruang yang ada. (lihat gambar berikut).

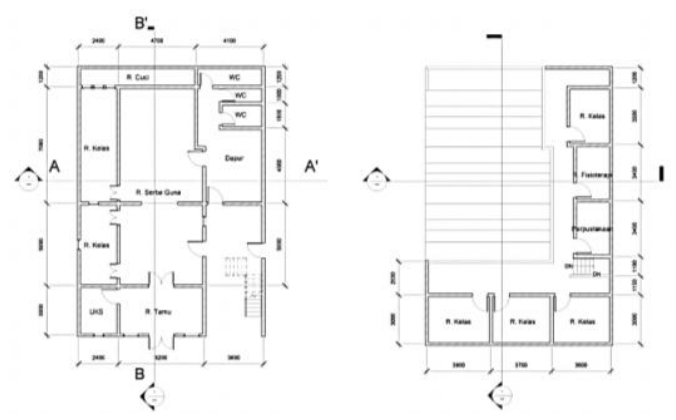

Gambar 2. Denah SLB Harmoni

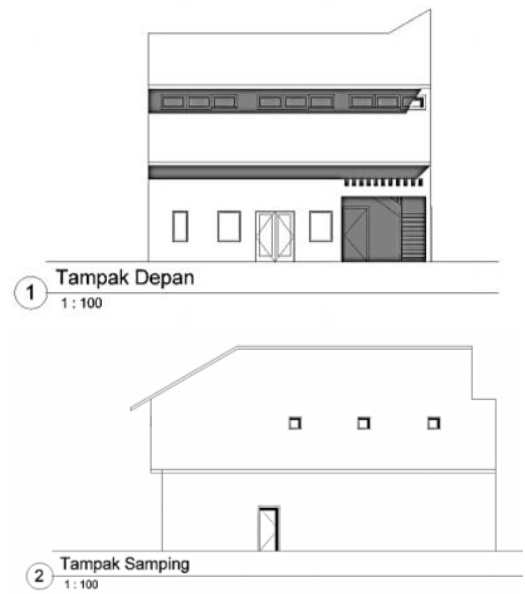

Gambar 3. Tampak SLB Harmoni Sumber : Singgih, dkk., 2015
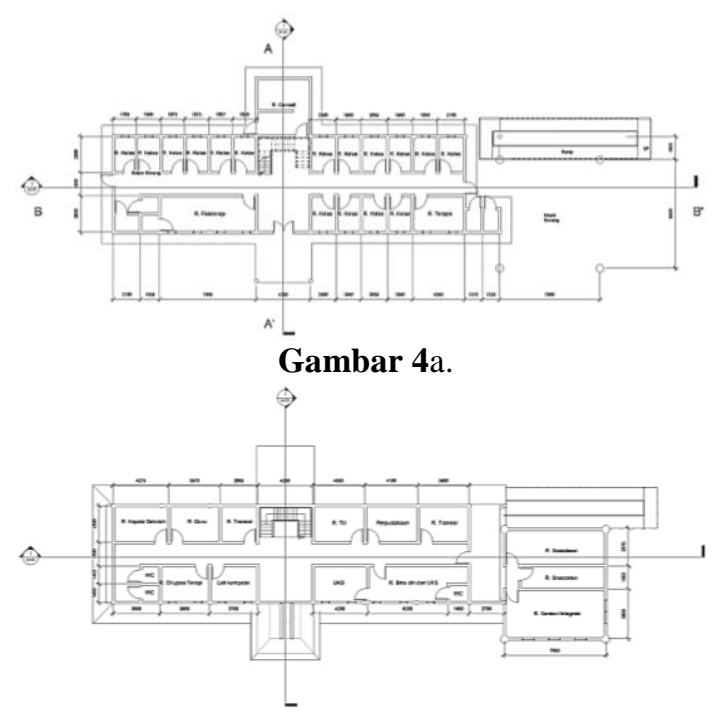

Gambar 4b.

Gambar 4a dan 4b. Denah Sekolah Autis Mitra Ananda

Sumber : Singgih, dkk., 2015
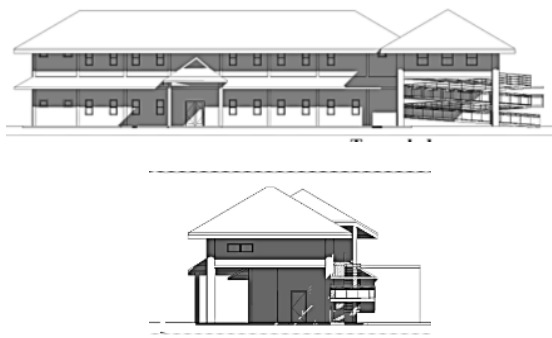

Gambar 5. Tampak Sekolah Autis Mitra Ananda Sumber : Singgih, dkk., 2015

Evaluasi teknis yang dilakukan terhadap obyek penelitian mengembangkan dari teori-teori di atas, yakni :

1. Zonning (pengelompokan spasial) dan organisasi ruang.

Zona ruang kelas (privat) di SLB Harmony tercampur dengan zona publik (ruang tamu) dan semi publik (ruang serbaguna), hal ini dapat membingungkan anak autis. Di Sekolah Mitra Ananda zona ruang kelas seluruhnya terletak di lantai 1 , lantai 2 untuk semi publik dan ruang privat (ruang guru, perpustakaan dan terapi lainnya). Lihat gambar 6.

Ruang serbaguna di SLB Harmony (di tengah-tengah lantai 1) dimanfaatkan untuk latihan pentas, ruang interaksi anak dan lain-lain (lihat gambar 6).
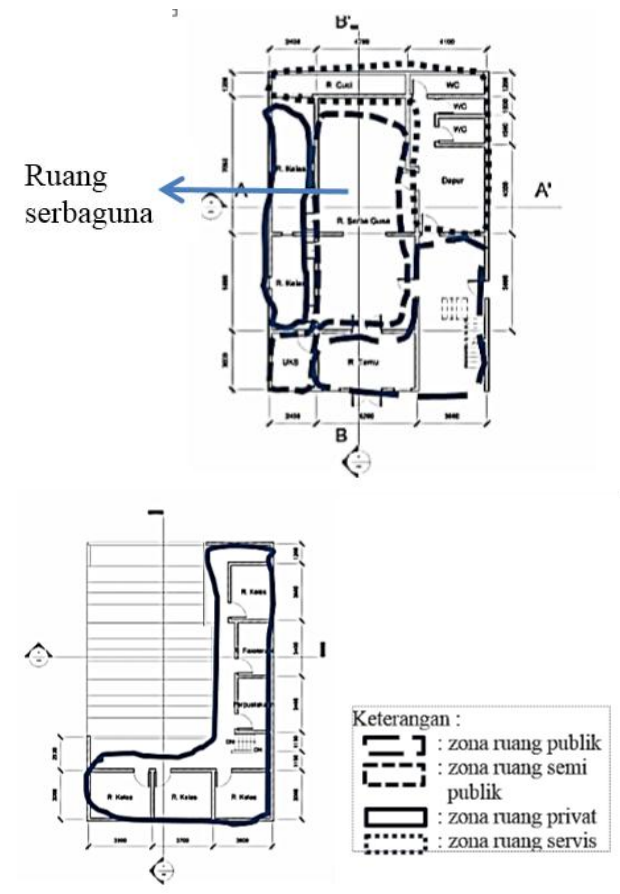

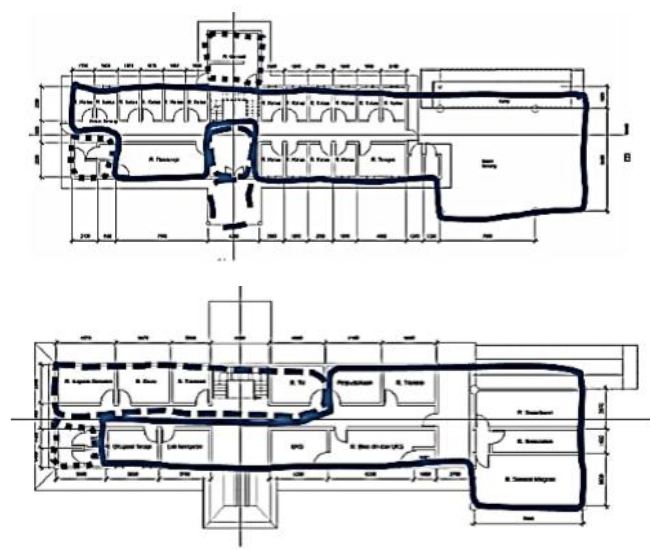

Gambar 6. Evaluasi terhadap zonnifikasi ruang

2. Konteks dan Komunitas (Context and Community).

Interaksi yang dilakukan dalam bangunan hanya interaksi antara anak autis dengan gurunya, interaksi dengan masyarakat luar dilakukan di tempat lain. SLB Harmony sudah memiliki ruang serbaguna untuk ruang interaksi, Sekolah Mitra Ananda belum memilikinya.

3. Way-finding dan Navigation.

Alur sirkulasi yang disediakan di SLB Harmony lantai 1 terpusat dengan ruang serbaguna di tengah, membingungkan bagi anak autis. Sirkulasi di lantai 2 linear dan lebih terarah. Sedangkan alur surkulasi di Sekolah Mitra Ananda berbentuk linear dan lebih terarah (lihat gambar 7).

Tidak ada penguatan atau perbedaan penekanan warna, pola, tekstur, katakata tertulis dan penanda di jalur sirkulasi atau ruang khusus lainnya.
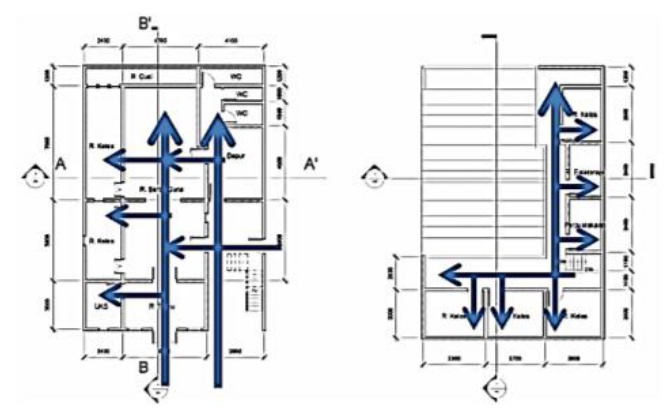
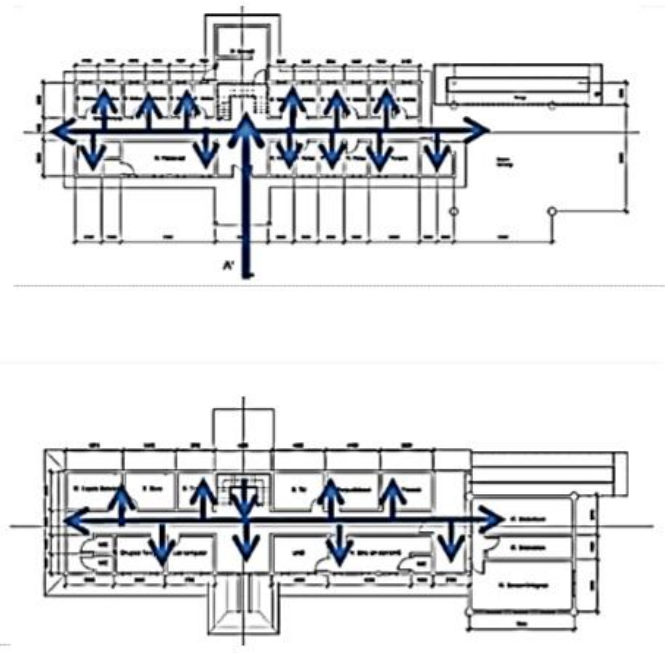

Gambar 7. Evaluasi terhadap sirkulasi

Seluruh dinding pada ruangan dicat seragam dengan warna krem (Mitra Ananda) dan hijau muda (Harmony). Way-finding dan navigation belum diterapkan dengan optimal.

4. Akustik, pencahayaan dan penghawaan alami/buatan.

Sistem peredaman bising (akustik) sama sekali belum diterapkan baik di SLB Harmony maupun di Sekolah Mitra Ananda. Bising yang berasal dari luar maupun dalam ruang terdengar jelas dan mengganggu konsentrasi anak autis.

Sistem pencahayaan alami di SLB Harmony menggunakan pencahayaan langsung dari bovenligh glass block dan pantulan dari jendela. Sedangkan pencahayaan buatan menggunakan pencahayaan langsung dengan lampu pijar. Sistem pencahayaan tersebut terlalu menyilaukan, kurang ideal bagi anak autis. Penghawaan alami yang tersedia di SLB Harmony berasal dari bovenligh roster berlobang yang terdapat di atas pintu dan jendela, terasa gerah dan tidak optimal (lihat gambar 8).

Sistem pencahayaan alami di Sekolah Mitra Ananda menggunakan pencahayaan langsung dari jendela kaca. Sistem tersebut terlalu menyilaukan, kurang ideal bagi anak autis. Sedangkan pencahayaan buatan menggunakan 
pencahayaan langsung dengan lampu down light.
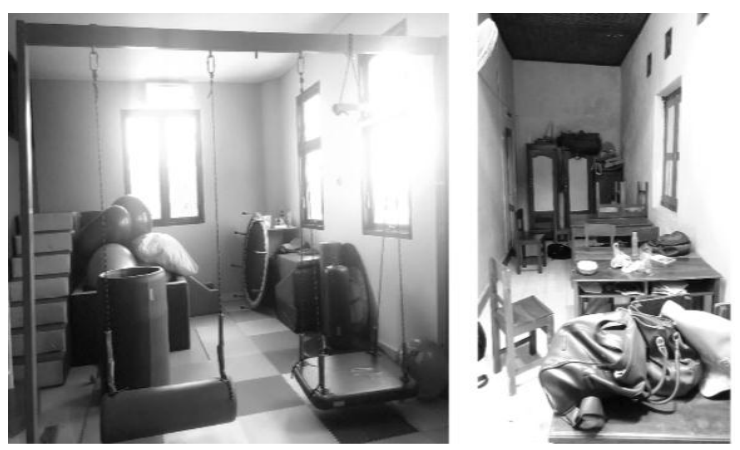

Gambar 8. Evaluasi Penghawaan dan Pencahayaan

Bukaan berupa jendela untuk pencahayaan dan penghawaan alami di Sekolah Mitra Ananda dan SLB Harmony setinggi lebih dari 1 meter dari lantai, ketinggian lubang bukaan tersebut lebih aman untuk anak autis. Sekolah Mitra Ananda menggunakan penghawaan buatan AC, terasa sejuk dan bisa membantu konsentrasi anak autis dalam beraktivitas. Penghawaan yang terkondisikan dengan baik sangat dibutuhkan dan membantu dalam mengurangi kegelisahan siswa (lihat gambar 8).

5. Keamanan dan jalur evakuasi penyelamatan kebakaran dan bencana alam.

Anak autis suka bergerak, namun jika mengalami gangguan motorik akan mengakibatkan keseimbangannya kurang stabil (Merry, 2008). Mebeleir dan elemen interior yang bertepi tajam berbahaya bagi anak autis.

SLB Harmony masih menggunakan mebeleir standar bertepi tajam seperti yang digunakan di sekolah normal pada umumnya.

Sekolah Mitra Ananda menggunakan mebeleir bertepi relatif tumpul dan reiling tangga serta ramp berbentuk pipa, sehingga lebih aman untuk anak autis.

SLB Harmony menggunakan jalur evakuasi berupa tangga untuk penyelamatan kebakaran dan bencana alam, yang juga berfungsi untuk tangga umum. Sedangkan di Sekolah Mitra Ananda, selain tangga juga telah disediakan ramp di samping bangunan.

\section{b. Evaluasi terhadap Fungsi Ruang}

Ruang di lantai 1 Sekolah Mitra Ananda digunakan untuk ruang kelas individu dan ruang kelas dengan 2 siswa. Sedangkan di lantai 1 SLB Harmony ruang dimanfaatkan untuk kelas bersama (4 hingga 6 siswa) bagi yang kondisinya belum stabil, dan lantai 2 untuk ruang kelas bersama bagi siswa-siswa yang telah relatif stabil (lihat gambar 9).

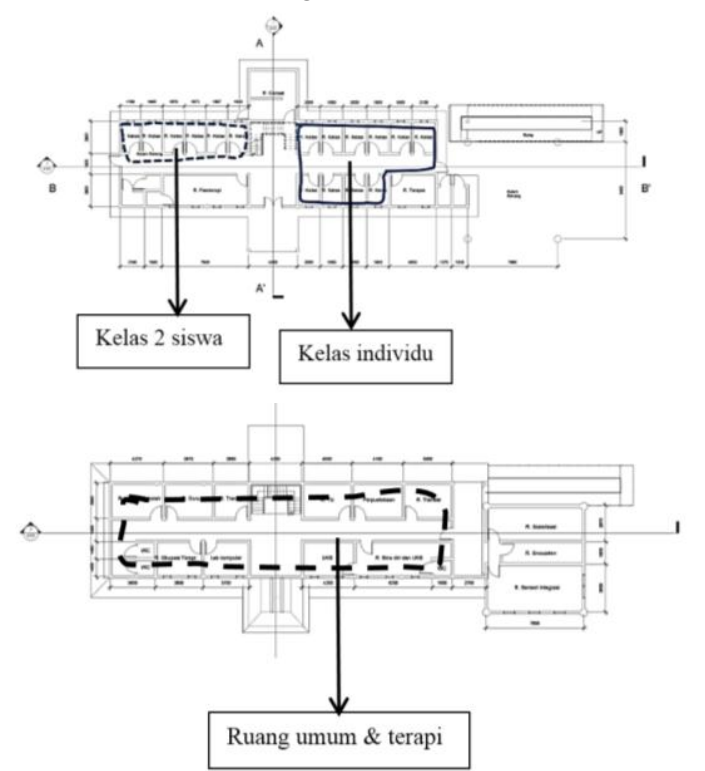

Gambar 9a.
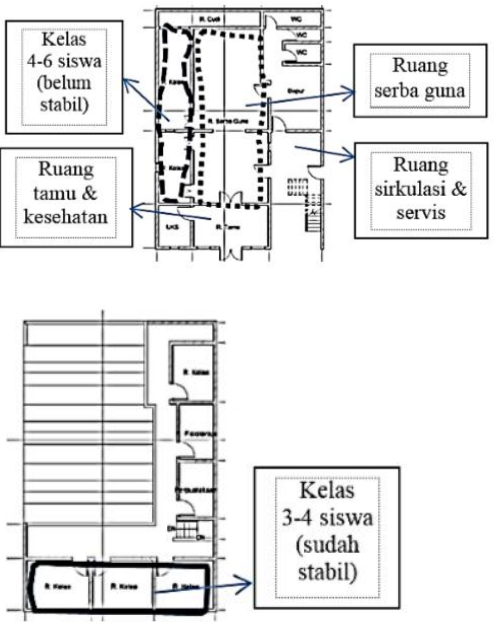

Gambar 9b.

Gambar 9a dan 9b. Evaluasi terhadap fungsi ruang 
Ketersediaan ruang di SLB Harmony sangat terbatas bila dibandingkan dengan Mitra Ananda, walaupun demikian kegiatan pembelajaran tetap bisa dilakukan dengan penggunaan ruang yang multi-fungsi (konsep variety). Ruang serbaguna Di SLB Harmony yang terletak di lantai 1 dimanfaatkan untuk berbagai kegiatan bersama, sedangkan di Sekolah Mitra Ananda kegiatan bersama dilakukan di koridor sekolah tersebut. Ruang kelas bagi anak dengan emosi belum stabil diletakkan di lantai 1 sehingga kegiatan anak lebih terkontrol dan aman, ruang kelas lantai 2 hanya untuk anak-anak yang penguasaan emosinya sudah stabil.

\section{c. Evaluasi terhadap Perilaku}

Lingkungan di mana manusia berada tidak sepenuhnya sesuai dengan apa yang dibutuhkan atau diinginkan, demikian halnya dengan anak autis yang memiliki sensitivitas tinggi terhadap lingkungan yang ada di mana ia berada. Anak autis kurang memiliki kepekaan sosial, akan tetapi terhadap lingkungan yang ada di sekitarnya anak autis mampu menyadari perbedaan-perbedaan kecil yang ada. Obyek rancang bukan hanya menjadi bangunan sebagai wadah aktivitas akan tetapi juga menjadi bagian dari aktivitas tersebut (Indarti, dkk., 2012).

Dari hasil penelitian perilaku anak-anak autis dapat digolongkan menjadi perilaku tidak patuh dan perilaku mengganggu/menyerang. Perilaku tidak patuh, ditunjukkan dengan tidak mau mengikuti pengarahan atau permintaan orangtua/guru. Perilaku mengganggu atau menyerang, biasanya dalam bentuk mengamuk/berteriak, menendang, memukul, menggigit dan sebagainya.

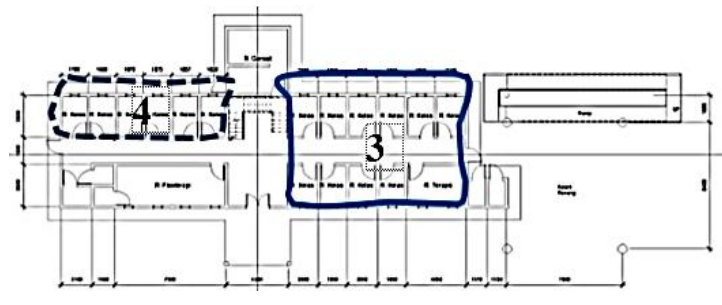

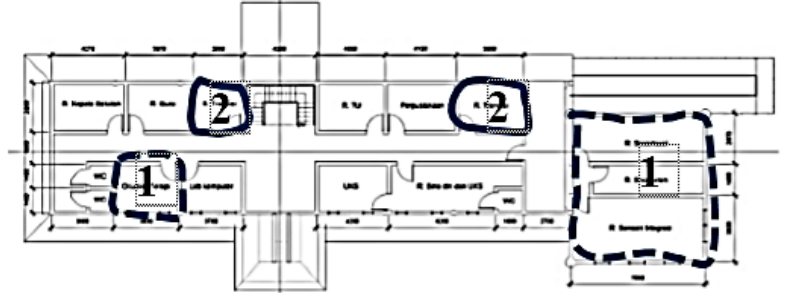

Gambar 10. Pewadahan perilaku di Sekolah Mitra Ananda

Di Sekolah Mitra Ananda, anak autis yang baru masuk (emosinya belum stabil) diterapi dulu di lantai 2 ruang (1), setelah terkendali dipindahkan ke ruang transisi (2), kemudian setelah dianggap mampu menerima pelajaran dipindahkan ke lantai 1 ruang kelas individu (3) dan selanjutnya apabila kondisi emosi, interaksi dan kemampuannya belajar meningkat dipindahkan ke kelas untuk 2 siswa (4). Lihat gambar 10.

Walaupun fasilitas pelayanan siswa di SLB Harmony tidak lengkap, akan tetapi SLB ini memiliki ruang serbaguna untuk kegiatan bersama di lantai 1 (lihat gambar 11). Ruang ini juga bisa dimanfaatkan sebagai tempat berlatih saat siswa akan mengadakan pentas kesenian dan lain-lain. Sekolah Mitra Ananda tidak memiliki ruang serbaguna. Kegiatan interaksi dilakukan di koridor yang ada di bangunan tersebut.

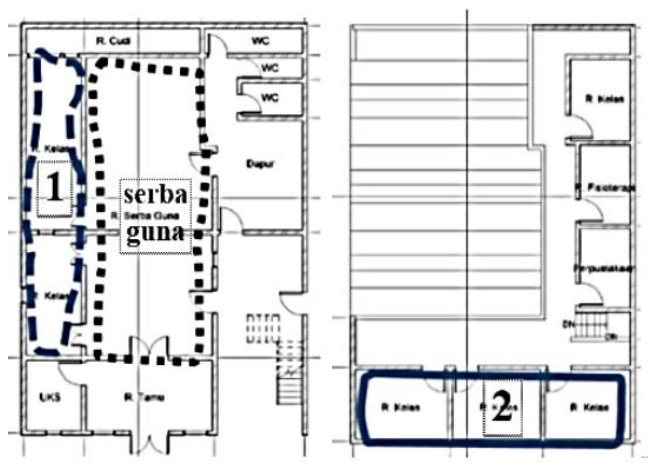

Gambar 11. Pewadahan perilaku di SLB Harmony

\section{A. Rekomendasi Penataan Ruang}

Melatih kemandirian anak autis dimulai dengan memberikan ruang agar mereka mampu menggunakan kemampuan mereka dalam menyelesaikan masalah, obyek rancang 
bukan hanya menjadi bangunan sebagai wadah aktivitas akan tetapi juga menjadi bagian dari aktivitas tersebut (Pambudi, 2017).

Dari hasil evaluasi tersebut di atas, dapat ditentukan rekomendasi bagi tata ruang bagi Sekolah anak autis di Surakarta dan sekitarnya sebagai berikut.

a. Zonning dan Organisasi Ruang.

1) Zona ruang dengan fungsi sejenis sebaiknya didekatkan, jalur pencapaiannya disesuaikan dengan proses kegiatan yang ada dalam bangunan, sistem sirkulasi yang digunakan satu arah atau linier. Sistim ini sudah diterapkan pada Sekolah Mitra Ananda.

2) Diperlukan ruang serbaguna (multi fungsi) untuk melaksanakan kegiatan ekstra kurikuler dan ruang interaksi, ruang multi fungsi dapat mewadahi banyak kegiatan tanpa menambah ruang.

b. Konteks dan Komunitas (Context and Community).

Perlu disediakan ruang yang dapat mewadahi kegiatan saling berinteraksi antara siswa dengan guru/pembimbing dalam satu sekolah serta interaksi dengan masyarakat luar, untuk melatih kemandirian siswa. Ruang tersebut dirancang dengan sistem sirkulasi satu arah. Ruang serbaguna tempat interaksi telah disediakan di SLB Harmony, akan tetapi perletakan di tengah bangunan (dengan sirkulasi memusat) sehingga membingungkan jalur/arah sirkulasi anak autis (sirkulasi satu arah).

\section{c. Way-finding dan Navigation.}

Jalur sirkulasi pada sekolah anak autis seharusnya satu arah atau linier dan diperjelas dengan menggunakan warna, pola, tekstur, kata-kata tertulis serta signage atau penanda (Hosny \& Anous, 2015). Warna yang digunakan seharusnya warna-warna muda yang teduh dan tidak mencolok (Pambudi, 2017), sehingga berefek menenangkan anak autis.

Karakter sensory sensitivities pada penyandang autis direspon dengan mengatur pengaruh lingkungan untuk menjaga konsentrasi dengan menghindari rangsangan berlebih seperti posisi jendela, ragam warna, kompleksitas bentuk dan lain-lain. Karakter autis memiliki kecenderungan visual thinking, karena itu diperlukan upaya untuk meningkatkan kejelasan (legibility) ciri visual ruang. Legibilitas ruang dapat dihadirkan dengan panduan ruang (spatial guidance), penyediaan jalur, arahan dan sistem penanda secara jelas melalui bentuk, warna, tekstur bahan dan lain-lain (Pambudi, 2017).

Anak autis merupakan visual thinker dan memiliki kelemahan yakni otaknya sangat rentan terkena overload memory input. Apabila terlalu banyak input visual yang masuk, dapat menimbulkan distraksi dan stress. Untuk itu penggunaaan kode harus sesederhana mungkin, sehingga dapat diidentifikasi dengan mudah oleh anak autis (Pambudi, 2017). Akustik, pencahayaan dan penghawaan alami atau buatan.

Salah satu karakteristik anak penyandang autis (Mayang Sari, 2004) antara lain adalah selektif berlebihan terhadap rangsang. Mereka akan sulit mengendalikan diri terhadap semua gangguan yang berasal dari luar yang antara lain yang berupa kebisingan. Untuk itu perlu adanya upaya peredaman bising melalui konfigurasi tata ruang dan pemasangan akustik (peredaman suara) pada dinding, lantai serta plafond.

Kriteria persyaratan akustik untuk ruang kelas menurut ANSI-S12.60 (Standar Kualitas Akustik Bangunan Sekolah) adalah bising lingkungan tidak boleh melebihi $35 \mathrm{dBA}$ dan $55 \mathrm{dBC}$ di seluruh bagian ruang kelas dengan waktu dengung tidak boleh lebih dari 0,6 detik (Mediastika, 2013).

Pencahayaan yang digunakan pada sekolah autis seharusnya menghindari silau dan silhouetting, dengan menggunakan pencahayaan tidak langsung dari pantulan atau biasan (lihat gambar 10).

Sistem pencahayaan untuk Sekolah autis seharusnya sebagai berikut (Suyatno, Astrini, \& Iyati, n.d.).

1) Menggunakan cahaya alami melalui jendela di bawah atap (clerestory), 
menggunakan bukaan pada atap (skylight), menggunakan jendela double glaszed yang mampu memantulkan panas hingga $85 \%$ dan meredam bisinghingga $70 \%$ serta menggunakan tirai penutup transparan (screening device).

2) Menggunakan cahaya buatan seperti penggunaan lampu neon modern berarmatur, cahaya dipantulkan oleh langit-langit dan dinding.

3) Intensitas yang cocok untuk anak autis adalah 70-80 untuk permukaan plafon, 30-50 untuk permukaan dinding, dan 20-30 untuk permukaan lantai. Temperatur yang cocok untuk anak autis adalah $30^{\circ}-35^{\circ} \mathrm{C}$.
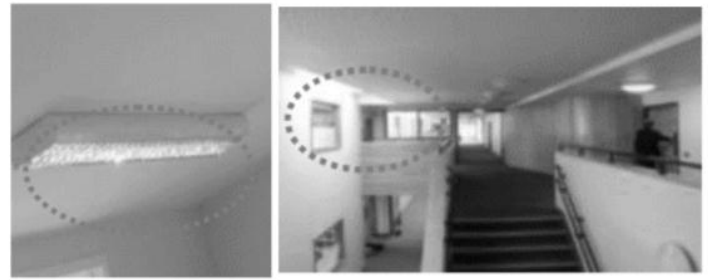

Gambar 10. Pencahayaan buatan dan alami (Suyatno et al., n.d.)

Kwalitas pencahayaan untuk rumah/ruang yang sehat sesuai KepMenKes. RI No. 829/Menkes/SK/VII/1999 yaitu pencahayaan alam dan/atau buatan langsung maupun tidak langsung dapat menerangi seluruh ruangan dengan intensitas penerangan minimal 60 lux dan tidak menyilaukan mata.

Untuk penghawaan menurut KepMenKes. RI No. 829/Menkes/SK/VII/1999 ventilasi yang baik dalam ruangan harus mempunyai syarat lainnya, di antaranya : Luas lubang ventilasi minimum 5\% dari luas lantai; udara yang masuk harus udara bersih, tidak tercemari; aliran udara diusahakan ventilasi silang jangan sampai terhalang oleh barang. Ketentuan kwalitas udara untuk ruang yang sehat adalah sebagai berikut : Suhu udara nyaman antara $18-30^{\circ} \mathrm{C}$; kelembaban antara $40-70 \%$; gas $\mathrm{SO}_{2}$ kurang dari 0,10 ppm per 24 jam; pertukaran udara 5 kali 3 per menit untuk setiap penghuni; gas $\mathrm{CO}$ kurang dari 100 ppm per 8 jam; gas formaldehid kurang dari $120 \mathrm{mg}$ per meter kubik. d. Keamanan dan jalur evakuasi penyelamatan kebakaran serta bencana alam.

Keamanan dimaksudkan sebagai rekayasa pada ruang dan furniture supaya aman digunakan oleh anak autis, yakni dengan menggunakan furniture dan elemen interior dengan tepi pejal/tidak tajam serta jendela kaca dengan ketinggian lebih dari $1 \mathrm{~m}$ dari lantai.

Keselamatan/evakuasi saat terjadi bahaya kebakaran atau bencana alam, dengan menyediakan tangga dan ramp. Strategi evakuasi harus merupakan suatu gerakan sirkulasi yang aman dan efektif yang dengan mudah dapat diakses oleh setiap individu dari setiap titik pada bangunan/ruang yang bersangkutan, langsung menuju ke tempat yang aman dan mudah dijangkau dari aliran evakuasi.

\section{KESIMPULAN}

Dari uraian tersebut di atas dapat ditarik kesimpulan bahwa kondisi zonning dan organisasi ruang di sekolah autis yang ada di Surakarta dan sekitarnya sebagian masih tercampur sehingga membingungkan anak autis. Bangunan tersebut juga belum memiliki tempat interaksi yang baik, tempat/ruang yang disediakan untuk interaksi dengan masyarakat terkesan seadanya. Selain hal itu, pada bangunan sekolah ini juga tidak ada penguatan/penekanan warna, tektur, pola, penanda pada jalur sirkulasi maupun ruangruang khusus yang penting.

Belum ada upaya peredaman kebisingan yang diterapkan pada bangunan, sistem pencahayaan yang digunakan kurang sempurna dan pengaturan penghawaan belum maksimal. Sistem keamanan pada mebeleir dan elemen interior kurang dipehatikan dan jalur evakuasi penyelamatan kebakaran serta bencana alam belum terencana dengan baik.

Penataan ruang yang direkomendasikan yakni ruang dengan zona sejenis dikelompokkan agar lebih mudah diingat dan dijangkau, organisasi ruang disusun sesuai dengan proses kegiatan yang terjadi dengan sistem sirkulasi yang searah/linier agar mudah pencapaiannya. Di dalam bangunan disediakan ruang/tempat 
interaksi antara anak autis, guru/pembimbing dan masyarakat, yang multi fungsi, agar bisa mewadahi semua kegiatan tanpa menambah ruang.

Memberikan penguatan/penekanan pada jalur sirkulasi maupun ruang-ruang khusus dengan warna, tekstur, pola dan penanda agar anak autis mudah mengingat dan mengenalinya. Pengaturan akustik (peredaman bising) dilakukan untuk mengatasi bising dari luar dan bising latar, sistem pencahayaan diatur untuk menghindari silau dan silhuet, sistem penghawaan diataur agar terasa sejuk/tidak pengap. Semua ini dilakukan untuk membantu konsentrasi anak autis dalam belajar.

Menghindari tepi tajam pada mebeleir dan elemen interior agar anak tidak terluka, karena anak autis kurang bisa mengontrol gerakannya. Jalur evakuasi penyelamatan kebakaran dan bencana alam dibuat dengan sistem sirkulasi linier serta mudah dicapai dan aman, agar mudah dan cepat dapat dijangkau saat terjadi kebakaran atau bencana alam.

\section{UCAPAN TERIMAKASIH}

Kami ingin mengucapkan banyak terima kasih kepada:

a. Pengelola Sekolah Autis Mitra Ananda dan pengelola SLB Harmoni yang telah memberikan kesempatan untuk melakukan observasi dan memberikan informasi bagi penelitian ini.

b. Tak lupa kami ucapkan terima kasih kepada Prodi Arsitektur Fakultas Teknik Universitas Sebelas Maret, yang telah memberikan kesempatan bagi kami untuk melakukan penelitian.

c. Kami juga mengucapkan terima kasih kepada LPPM Universitas Sebelas Maret yang telah memerikan supporting dana bagi penelitian ini di tahun 2015 .

\section{REFERENSI}

Akman, E. (2002). Post Occupancy Evaluation with Building Values Approach.

Altenmüller-lewis, U. (2017). Designing Schools for Students on the Spectrum Designing Schools for Students on the Spectrum. The Design Journal.
Routledge.

https://doi.org/10.1080/14606925.2017.1 352738

Hosny, I., \& Anous, I. (2015). The impact of Interior Design in educational spaces for children with Autism. American International Journal of Research in Humanities, Arts and Social Sciences, 90-101.

Huberman, A. M. (1994). Qualitative Data Analysis (3rd ed.). Arizona: SAGE. Retrieved from file:///C:/Users/user/Downloads/Miles et al. 2013 Qualitative Data Analysis Chapter 4.pdf

Judarwanto, W. S. (1943). Deteksi dini dan skrening autis. Retrieved from http://komunitas-

puterakembara.net/joomla/images/stories /widodo/deteksi_dini.pdf

Mayang Sari, S. (2004). Konsep Desain Partisipasi dalam Desain Interior Ruang Terapi Perilaku Anak Autis. Journal Pusat Penelitian, 90-96. Retrieved from https://media.neliti.com/media/publicatio ns/217923-konsep-desain-partisipasidalam-desain-i.pdf

Mediastika, C. (2013). Hemat Energi Dan Lestari Lingkungan.

Moore, G. . (1979). Environment Behaviore Study. In Introduction to Architecture. New York: McGraw-Hill.

Pambudi, F. I. (Universitas N. Y. (2017). Pelaksanaan Pembelajaran Pendidikan Jasmani Adaptif untuk Anak Autis di Sekolah Khusus Autis Bina Anggita Yogyakarta.

Setiawan, B. (2010). Arsitektur Lingkungan dan Perilaku. Yogyakarta: Gadjah Mada University Press.

Suyatno, V. P., Astrini, W., \& Iyati, W. (n.d.). Rekayasa Tata Cahaya Alami pada Ruang Kelas Sekolah Autis Laboratorium Universitas Negeri Malang. 